\title{
Protection from interleukin 1 induced destruction of articular cartilage by transforming growth factor $\beta$ : studies in anatomically intact cartilage in vitro and in vivo
}

\author{
Henk $M$ van Beuningen, Peter M van der Kraan, Onno J Arntz, Wim B van den Berg
}

\begin{abstract}
The modulation of interleukin 1 (IL-1) effects on proteoglycan metabolism in intact murine patellar cartilage by transforming growth factor $\beta$ (TGF- $\beta$ ) was investigated in vitro and in vivo. In vitro TGF- $\beta$ (400 pmol/1) had no effect on basal proteoglycan degradation. Proteoglycan degradation induced by IL-1, however, was suppressed by TGF- $\beta$ in serum free medium alone and in medium supplemented with $0.5 \mu \mathrm{g} / \mathrm{ml}$ insulin-like growth factor 1 . This suggests a specific regulatory role for TGF- $\beta$ under pathological conditions. In contrast with the suppression of breakdown, synthesis of proteoglycans was stimulated by TGF- $\beta$ for both basal and IL-1 suppressed proteoglycan synthesis in cultures without insulin-like growth factor. In the presence of insulin-like growth factor no extra effect of TGF- $\beta$ on proteoglycan synthesis was observed. With insulin-like growth factor, however, TGF- $\beta$ potentiated the ex vivo recovery of $\mathrm{IL-1}$ induced suppression of proteoglycan synthesis. Analogous to the in vitro effects, TGF- $\beta$ injected intraarticularly suppressed IL-1 induced proteoglycan degradation. Furthermore, TGF- $\beta$ injected into the joint counteracted IL-1 induced suppression of proteoglycan synthesis. This indicates that in vivo also TGF- $\beta$ can ameliorate the deleterious effects of IL-1 on the cartilage matrix.
\end{abstract}

(Ann Rheum Dis 1993; 52: 185-191)

Department of Rheumatology, University Hospital St

Radboud, Nijmegen,

The Netherlands

$H M$ van Beuningen

P M van der Kraan

O J Arntz

W B van den Berg

Correspondence to:

Dr H M van Beuningen,

Department of

Rheumatology, St

Radboudhospital, Geert

Grooteplein Zuid 8, 6525

GA Nijmegen, The

Netherlands

Accepted for publication

29 September 1992
Many studies have provided evidence for interleukin 1 (IL-1) being a key mediator in inflammation in general and in arthritis in particular. It causes an influx of inflammatory cells into the joint, ${ }^{1-4}$ suppresses chondrocyte proteoglycan synthesis, and stimulates cartilage degradation..$^{5-12}$ Interleukin 1 concentrations in arthritic joints are increased ${ }^{13-15}$ and IL-1 could be responsible for most of the cartilage damage that is characteristic of arthritis.

It has been found that the ubiquitous and multifunctional regulatory peptide transforming growth factor $\beta$ (TGF- $\beta$ ) can counteract the effects of IL-1 on several cell types, ${ }^{16}{ }^{17}$ including chondrocytes. ${ }^{18}{ }^{19}$ In arthritis it could be an important factor because of its immunosuppressive functions $\mathrm{s}^{16}{ }^{20-25}$ and its effects on articular cartilage. With regard to articular cartilage it was reported that TGF- $\beta$ in vitro can suppress IL-1 induced proteoglycan degradation in monolayers of articular chondrocytes and in sliced cartilage. ${ }^{18} 19$ As TGF- $\beta$ concentrations in arthritic joint fluids $^{26-29}$ are in the range yielding optimum TGF- $\beta$ effects on chondrocytes in vitro, ${ }^{30-32}$ TGF- $\beta$ could play an important regulatory part in cartilage destruction during arthritis.

In the present study we investigated TGF$\beta$ modulation of IL-1 effects on proteoglycan degradation and proteoglycan synthesis in intact articular cartilage. We studied this modulation in vitro in basal medium, to confirm earlier studies, ${ }^{18}{ }^{19}$ and in the presence of insulin-like growth factor, which is the major stimulatory factor, with respect to cartilage proteoglycan synthesis, in serum and synovial fluid. ${ }^{33} 34$ In addition to these more extensive in vitro experiments, we showed for the first time that TGF- $\beta$ injected into the joint modulates the effects of IL-1 on proteoglycan metabolism.

Materials and methods

ANIMALS

C57B $1 / 10$ mice aged 12 weeks or 18 months were used. They were fed a standard diet and tap water ad libitum.

CHEMICALS

RPMI 1640 culture medium (Dutch modification) was obtained from Flow Laboratories (Irvine, UK). A 10-40 pg sample of IL-1 $\alpha$ corresponded to one unit in the lymphocyte activating factor assay. Transforming growth factor $\beta_{1}$, purified from human platelets (Calbiochem, La Jolla, CA, USA) was decontaminated of trifluoroacetic acid and acetonitrile with a vacuum concentrator (Savant Instruments, Formingdale, NY, USA) and resuspended in $4 \mathrm{mM} \mathrm{HCl}$ for activation. Recombinant human insulin-like growth factor 1 (Boehringer, Mannheim, Germany) was dissolved in $0.1 \mathrm{M}$ acetic acid (Merck, Darmstadt, Germany). All medium used in these experiments was supplemented with $0.1 \%$ ultrapure bovine serum albumin (Sigma, 
St Louis, MO, USA). In vivo injections with TGF- $\beta$ were performed with purified human TGF- $\beta_{1}$. The purity of TGF- $\beta$ was verified using sodium dodecylsulphate polyacrylamide gel electrophoresis, showing only a single 25 kilodalton band. An extra band was visible after reduction. A neutralising antibody to TGF- $\beta$ (1D11.16) completely blocked the IL1 inhibiting effect of this TGF- $\beta$ on IL-1 induced production of IL-2 by NOB-1 cells.

IN VITRO EFFECTS OF INTERLEUKIN $1 /$

TRANSFORMING GROWTH FACTOR $\beta$ ON

CARTILAGE PROTEOGLYCAN METABOLISM

Mice were killed by cervical dislocation and the whole patellae, with a standard amount of surrounding tissue, were dissected from the knee joints as described by van den Berg et al. ${ }^{35}$ In studies on proteoglycan degradation patellae were prelabelled with $\left[{ }^{35} \mathrm{~S}\right]$ sulphate for three hours and rinsed to remove nonincorporated label before culture with IL-1 and growth factors. Six patellae were placed in $1 \mathrm{ml}$ of incubation medium consisting of RPMI 1640 supplemented with L-glutamine (2 $\mathrm{mmol} / \mathrm{l})$, pyruvate $(1 \mathrm{mmol} / \mathrm{l})$, and gentamycin $(40 \mu \mathrm{g} / \mathrm{ml})$ at $37^{\circ} \mathrm{C}$ in a humidified $5 \%$ carbon dioxide atmosphere. At the start of the incubation, TGF- $\beta(10 \mathrm{ng} / \mathrm{ml}=400 \mathrm{pmol} / \mathrm{l})$ or IL-1 $(30 \mathrm{U} / \mathrm{ml})$, or both, were added, alone or in combination with $0.5 \mu \mathrm{g} / \mathrm{ml}$ insulin-like growth factor 1. Proteoglycan degradation experiments were stopped after 24 hours of culture. In proteoglycan synthesis experiments the medium was changed at 24 hours and cultures were continued for another 24 hours to obtain a maximum effect of IL-1 on proteoglycan synthesis. Patellae were then labelled with $\left[{ }^{35} \mathrm{~S}\right]$ sulphate for two hours at the end of the incubation with IL-1 and growth factors. The patellae were fixed, decalcified, punched out of the surrounding tissue, and dissolved as described elsewhere. ${ }^{35}$ The ${ }^{35} \mathrm{~S}$ content of each patella, which is a reliable measure of cartilage proteoglycan production, ${ }^{36}$ was measured by liquid scintillation analysis.

IN VIVO EFFECTS OF INTERLEUKIN $1 /$ TRANSFORMING GROWTH FACTOR $\beta$ ON CARTILAGE PROTEOGLYCAN METABOLISM Intra-articular injections

Transforming growth factor $\beta(40,200$, or $1000 \mathrm{ng} / 6 \mu \mathrm{l}$ ) was injected into the joint space of the right knee, and the contralateral joint received an equal volume $(6 \mu \mathrm{l})$ of phosphate buffered saline (PBS). One hour after the TGF- $\beta$ injections IL- 1 (30 U) was injected into the right knee while the left knee received a second injection of PBS. In controls for the effects of IL- 1 or TGF- $\beta$ alone, respectively, the first or the second injection into the right knee was performed with PBS. In vivo experiments on proteoglycan degradation were preceded by a prelabelling of articular cartilage with $74 \mathrm{kBq}\left[{ }^{35} \mathrm{~S}\right]$ sulphate/g body weight, injected subcutaneously 24 hours before the intra-articular injections.

\section{Histology}

Histology was used to compare cartilage depletion and cellular influx into the joints treated with IL-1, TGF- $\beta$, or a combination of both. Whole knee joints were dissected and processed as described elsewhere. ${ }^{37}$ Semiserial frontal sections were stained with safranin $\mathrm{O}$ or haematoxylin-eosin to be used in studies on cartilage proteoglycan depletion and cellular influx respectively.

STATISTICAL ANALYSIS

Differences between experimental groups were tested using Student's $t$ test, unless stated otherwise.

\section{Results}

EFFECT OF TRANSFORMING GROWTH FACTOR $\beta$ ON INTERLEUKIN 1 INDUCED PROTEOGLYCAN DEGRADATION IN VITRO

Although basal proteoglycan turnover rates in murine cartilage are already relatively high, markedly enhanced proteoglycan degradation was observed in patellae cultured without growth factors. In one day cultures of patellae in medium without insulin-like growth factor 1 (table 1) $52 \%$ of the ${ }^{35} \mathrm{~S}$-labelled proteoglycans was released from the patellar cartilage. Interleukin 1 caused a small but significant extra release of $27 \%$ of the label compared with control cultures. In IL-1 treated patellae the release of labelled sulphate was significantly suppressed by $400 \mathrm{pmol} / \mathrm{l}$ TGF- $\beta$. This regulation was also present and of the same order of magnitude in cartilage derived from old animals (18 months old; data not shown).

Similar studies were performed in the presence of insulin-like growth factor 1 (0.5 $\mu \mathrm{g} / \mathrm{ml})$. In these cultures the release of ${ }^{35}$ S-labelled proteogylcans was $13 \%$ (table 1 ). This is comparable with the proteogylcan degradation measured in patellar cartilage in vivo. ${ }^{38} 39$ Interleukin 1 caused a significant extra release of $35 \%$ of the label compared with control cultures. Also under these conditions (with insulin-like growth factor 1), TGF- $\beta$ diminished only the IL-1 induced proteoglycan release ( $37 \%$ reduction), not the IL-1 independent release. This indicates that suppression of

Table 1 In vitro modulation of interleukin 1 (IL-1) induced proteoglycan degradation by transforming growth factor $\beta(T G F-\beta)$

\begin{tabular}{|c|c|c|}
\hline \multirow[b]{2}{*}{ Addition $\$$} & \multicolumn{2}{|l|}{${ }^{35} S$ proteoglycan content ${ }^{*}$} \\
\hline & No addition & $\begin{array}{l}\text { Insulin-like } \\
\text { factor growth } 1\end{array}$ \\
\hline $\begin{array}{l}\text { No addition } \\
\text { TGF- } \beta \\
\text { IL-1 } \\
\text { IL- } 1+\text { TGF- } \beta\end{array}$ & $\begin{array}{l}715(134) \\
760(164)(\mathrm{NS}) \\
522(119)\left(\mathrm{p}<10^{-4} \dagger\right) \\
596(104)(\mathrm{p}<0.05 \ddagger)\end{array}$ & $\begin{array}{l}1296(268) \\
1192(253)(\mathrm{NS}) \\
849(164)\left(\mathrm{p}<10^{-5}\right) \\
1023(224)(\mathrm{p}<0.05)\end{array}$ \\
\hline \multicolumn{3}{|c|}{ 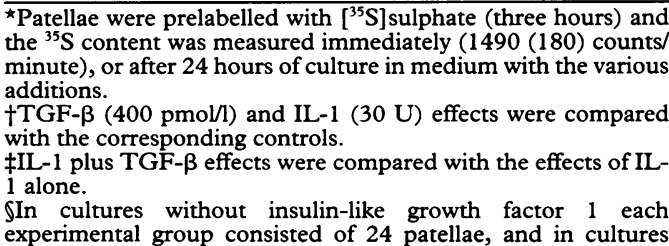 } \\
\hline
\end{tabular}
with insulin-like growth factor 1 consisted of 18 patellae. 
Table 2 In vitro modulation of interleukin 1 (IL-1) induced suppression of proteoglycan synthesis by transforming growth factor $\beta$ (TGF- $\beta$ )

\begin{tabular}{|c|c|c|}
\hline \multirow[b]{2}{*}{ Addition $\$$} & \multicolumn{2}{|c|}{$\left.{ }^{35} S\right]$ sulphate incorporation * } \\
\hline & No addition & $\begin{array}{l}\text { Insulin-like } \\
\text { factor growth } 1\end{array}$ \\
\hline $\begin{array}{l}\text { No addition } \\
\text { TGF- } \beta \\
\text { IL-1 } \\
\text { IL-1 + TGF- } \beta\end{array}$ & $\begin{array}{l}459(78) \\
594(90)(\mathrm{p}<0.001 \dagger) \\
224(78)\left(\mathrm{p}<10^{-6}\right) \\
325(112)(\mathrm{p}<0.001 \ddagger)\end{array}$ & $\begin{array}{l}1568(302) \\
1411(381)(\mathrm{NS}) \\
470(112)\left(\mathrm{p}<10^{-6}\right) \\
515(202)(\mathrm{NS})\end{array}$ \\
\hline
\end{tabular}

*Patellae were pulse labelled as a measure of proteoglycan synthesis with $\left[{ }^{35} \mathrm{~S}\right]$ sulphate either directly (1120 (198) counts minute), or after 48 hours of culture in medium with the various additions.

†TGF- $\beta$ (400 pmol/l) and IL-1 (30 U) effects were compared with the corresponding controls.

$\neq I \mathrm{IL}-1$ plus TGF- $\beta$ effects were compared with the effects of IL1 alone.

In cultures without insulin-like growth factor 1 each In cultures without insulin-like growth factor 1 each
experimental group consisted of 36 patellae, and in cultures with insulin-like growth factor 1 consisted of 18 patellae.

IL- 1 induced release by TGF- $\beta$ is not a general suppression of degradation, but a specific regulation that counteracts IL-1 effects.

EFFECT OF TRANSFORMING GROWTH FACTOR $\beta$ ON INTERLEUKIN 1 INDUCED SUPPRESSION OF CHONDROCYTE PROTEOGLYCAN SYNTHESIS IN VITRO

As cartilage homeostasis is the result of a balance between degradation and synthesis, in addition to proteoglycan breakdown we also studied proteoglycan synthesis. In the absence of insulin-like growth factor 1 (table 2), proteoglycan synthesis rapidly decreased during culture. Suppression of $\left[{ }^{35} \mathrm{~S}\right]$ sulphate incorporation after two days was $59 \%$ compared with synthesis immediately after the dissection of patellae. Interleukin 1 caused $52 \%$ extra suppression of proteoglycan synthesis compared with synthesis after parallel cultures without the cytokine. Addition of TGF- $\beta$ (400 pmol/1) led to a stimulation of proteoglycan synthesis, both with and without
IL-1. In the presence of insulin-like growth factor 1 (table 2) the proteoglycan synthesis was stimulated to $140 \%$ of synthesis levels measured immediately after dissection of patellae. Interleukin 1 caused $70 \%$ suppression of patellar proteoglycan synthesis compared with cultures without the cytokine. Under insulin-like growth factor conditions, TGF- $\beta$ had no extra effect on proteoglycan synthesis in both IL-1 treated and non-treated patellae.

RESTORATION OF INTERLEUKIN 1 SUPPRESSED PROTEOGLYCAN SYNTHESIS

To conserve articular cartilage extracellular matrix integrity it is of utmost importance that IL-1 induction of matrix proteoglycan depletion is downregulated, but repair of established depletion is also a crucial mechanism. Therefore, we studied TGF- $\beta$ effects in a phase of ex vivo recovery of IL-1 induced suppression of proteoglycan synthesis. Transforming growth factor $\beta$ clearly enhanced restoration of the proteoglycan synthesis after IL-1 induced suppression (figure). In these experiments TGF- $\beta$ caused an extra stimulation, superimposed on stimulating effects of insulinlike growth factor or serum. More specifically, TGF- $\beta$ prolonged insulin-like growth factor stimulation of proteoglycan synthesis and caused an accelerated stimulation of proteoglycan synthesis in cultures with $30 \%$ murine serum. Effects of TGF- $\beta$ on proteoglycan synthesis in control patellae (no IL-1 treatment) in four day cultures in the presence of insulin-like growth factor 1 or serum were minimal (data not shown).

\section{EFFECTS OF INTRA-ARTICULARLY INJECTED}

TRANSFORMING GROWTH FACTOR $\beta$

To answer the question of whether modulation of IL-1 effects by TGF- $\beta$ is also possible in
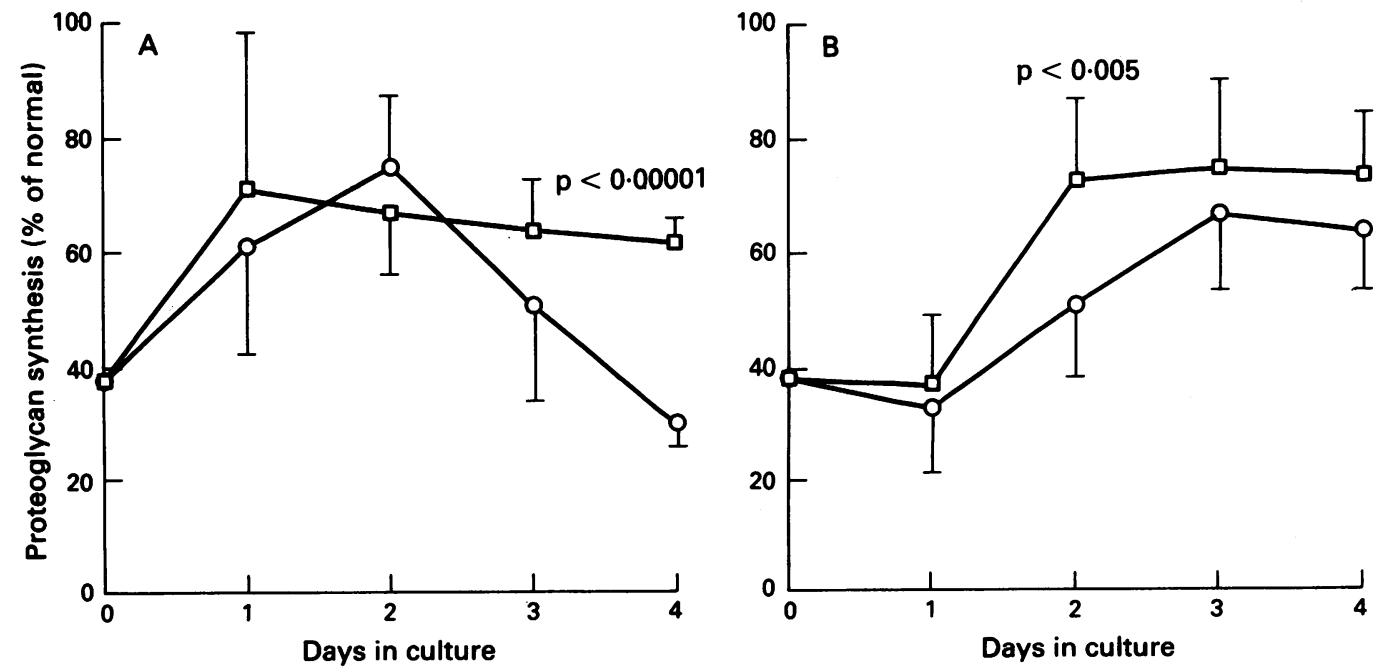

Effect of transforming growth factor $\beta$ (TGF- $\beta$ ) (400 pmoll) on ex vivo recovery of proteoglycan synthesis after in vivo suppression induced by interleukin 1 (IL-1). One day after intra-articular injection of IL-1 (3OU) the patellae were dissected and cultured with insulin-like growth factor $(A)$ or $30 \%$ murine serum $(B)$. The effect of TGF- $\beta$ on proteoglycan synthesis was determined at different times. Proteoglycan synthesis was expressed as a percentage of normal proteoglycan synthesis. Each value represents the mean (SD) of 18 patellae (from three different experiments). At the start of the culture synthesis. Each value represents the mean (SD) of 18 patellae (from three different experiments). At the start of the culture
$\left.3^{5} S\right]$ sulphate incorporation in IL-1 treated patellae was 325 (43) counts/min, whereas in normal, untreated patellae it was 855 (157). Transforming growth factor $\beta$ also had significant stimulatory effects when these data were analysed using three way ANOVA. () With TGF- $\beta$; (O) without TGF- $\beta$. 
Table 3 Modulation of interleukin 1 (IL-1) induced stimulation of proteoglycan release in vivo

\begin{tabular}{ll}
\hline Treatment $\$$ & ${ }^{35}$ S proteoglycan content of cartilage \\
\hline IL-1 & R $178(51)(77 \%)$ \\
& L $230(69)(\mathrm{n}=30)$ \\
IL-1 + 40 ng TGF- $\beta$ & R $200(50)(88 \%) ; \mathrm{p}=0.0116^{\star}$ \\
& $\mathrm{L} 226(57)(\mathrm{n}=30)$ \\
$\mathrm{IL}-1+1000$ ng TGF- $\beta$ & $\mathrm{R} 223(36)(91 \%) ; \mathrm{p}=0.0092^{\star}$ \\
& $\mathrm{L} 245(38)(\mathrm{n}=12)$ \\
40 ng TGF- $\beta$ & $\mathrm{R} 217(50)(90 \%) ; \mathrm{p}=0.042 \dagger$ \\
& $\mathrm{L} 242(37)(\mathrm{n}=18)$ \\
& $\mathrm{R} 208(59)(90 \%) ; \mathrm{p}=0.0015 \dagger$ \\
& $\mathrm{L} 232(56)(\mathrm{n}=30)$
\end{tabular}

ॠEffect of the combination of IL- 1 and TGF- $\beta$ on release of labelled proteoglycans was compared with the release induced by IL-1 alone.

treated (R) and contralateral (L) patellae of each individual animal were compared by Student's $t$ test for paired samples.

TTwenty four hours after $\left.{ }^{35} S\right]$ sulphate was injected subcutaneously, IL-1/transforming growth factor $\beta$ (TGF- $\beta$ ) was injected into the right knee joint. The amount of ${ }^{35}$ sas inject S-labelled proteoglycan in the patellae was determined after another twenty four hour period. $R$ is the ${ }^{35} S$ content of the righ (experimental) patellae, and $\mathrm{L}$ of the left (untreated) patella of the same animals. Groups of six mice were used; $n=30$ represents five different experiments.

vivo, we studied patellar proteoglycan metabolism after injection of both IL-1 and TGF$\beta$ into the knee joint. Cartilage proteoglycans were prelabelled with a single subcutaneous injection of $\left[{ }^{35} \mathrm{~S}\right]$ sulphate at day -1 . Interleukin $1(30 \mathrm{U})$ injected intra-articularly at day 0 caused $23 \%$ release of labelled proteoglycans within 24 hours compared with saline injection (table 3 ). When TGF- $\beta$ was injected one hour before IL-1 into the murine knee, the release of labelled proteoglycans in a 24 hour chase period was reduced. This suppression of IL-1 induced proteoglycan degradation was significant in the $40 \mathrm{ng}$ and the $1000 \mathrm{ng}$ TGF$\beta$ doses. No dose response effect was seen in this dose range. Surprisingly, TGF- $\beta$ injected alone (40 or $200 \mathrm{ng}$ ) significantly stimulated proteoglycan degradation, which may mask part of the protection against IL-1 induced proteoglycan degradation offered by TGF- $\beta$.

We also studied proteoglycan synthesis after intra-articular injections of TGF- $\beta$ or IL- 1 , or both. Proteoglycan synthesis was measured ex vivo in patellae isolated one day after injection. Interleukin 1 caused $57 \%$ suppression of proteoglycan synthesis compared with normal synthesis (table 4). The combination of IL-1 with 40 or 200 ng TGF- $\beta$ significantly decreased this suppression. Again, no dose response effect of TGF- $\beta$ was seen, suggesting that the $40 \mathrm{ng}$ dose already yields the maximum effect. Transforming growth factor $\beta$ alone did not influence proteoglycan synthesis in vivo.

Histology (not shown) showed that the injected TGF- $\beta$ had a clear chemoattractive capacity. At six hours and to a lesser extent at 24 hours after injection, considerable infiltration and exudation of inflammatory cells was seen. The predominant cells were polymorphonuclear leucocytes. In combination with IL-1, the injected TGF- $\beta$ had an additive effect in mediating the attraction of inflammatory cells. Our histology was not suited to confirm the protective effect of TGF$\beta$ because single IL-1 injections caused no visible proteoglycan depletion in articular cartilage in the mouse, as determined with
Table 4 Modulation of interleukin 1 (IL-1) induced suppression of proteoglycan synthesis in vivo

\begin{tabular}{|c|c|}
\hline Treatment $\$$ & Proteoglycan synthesis in cartilage \\
\hline IL-1 & $\begin{array}{l}486(191)(43 \%) \\
119(205)(n=18)\end{array}$ \\
\hline $\mathrm{IL}-1+40 \mathrm{ng}$ TGF- $\beta$ & $\begin{array}{l}\text { R } 629(76)(56 \%) ; p=0.007^{\star} \\
\text { L } 1130(217)(n=18)\end{array}$ \\
\hline IL-1 + 200 ng TGF- $\beta$ & $\mathrm{R} 646(119)(59 \%) ; \mathrm{p}=0.006^{\star}$ \\
\hline 40 ng TGF- $\beta$ & R $1116(179)(103 \%)$; NSt \\
\hline 200 ng TGF- $\beta$ & $\begin{array}{l}\mathrm{R} 1204(247)(106 \%) ; \mathrm{NS}+ \\
\mathrm{L} 1135(224)(\mathrm{n}=18)\end{array}$ \\
\hline
\end{tabular}

ॠProteoglycan synthesis after treatment with the combination of IL- 1 and TGF- $\beta$ was compared with proteoglycan synthesis after treatment with IL-1 alone.

$\dagger$ Treated $(R)$ and contralateral untreated $(L)$ patellae were compared.

§Twenty four hours after intra-articular injection of IL$1 /$ transforming growth factor $\beta$ (TGF- $\beta$ ) patellae were dissected and labelled with $\left.{ }^{35} \mathrm{~S}\right]$ sulphate for two hours as a measure of proteoglycan synthesis. $R$ is the ${ }^{35} \mathrm{~S}$ incorporation in the proteoglycan synthesis. $R$ is the $S$ incorporation in the right experimental) patellae and $\mathrm{L}$ in the left (untreated) patellae of the same animals. Groups of six mice were used; $n=18$
represents three different experiments.

safranin $O$ staining. Studies using repeated injections of IL-1 alone or in combination with TGF- $\beta$ are in progress.

\section{Discussion}

To study the effects of combinations of cytokine and growth factors on articular cartilage proteoglycan synthesis we cultured anatomically intact patellar cartilage embedded in a minimum area of surrounding tissue. ${ }^{35}$ Other workers have used sliced cartilage or isolated chondrocytes in the absence of underlying bone and synovial tissue. ${ }^{18} 1940$

We used an IL-1 concentration yielding the maximum effects on patellar cartilage proteoglycan metabolism. The chosen TGF- $\beta$ concentration $(10 \mathrm{ng} / \mathrm{ml})$ has been reported to have an optimum effect on chondrocytes and is physiologically relevant because comparable concentrations of active TGF- $\beta$ have been found in arthritic joints. ${ }^{26}{ }^{28}$ For the first time we tested the effects of TGF- $\beta$ in the presence of insulin-like growth factor 1 . In an attempt to create a physiologically relevant situation we used an insulin-like growth factor 1 concentration equal to the levels measured in murine serum samples.

We found that in the presence of insulin-like growth factor 1 the spontaneous release of proteoglycan from cultured cartilage was reduced, reaching levels comparable with basal proteoglycan release in vivo. ${ }^{38}{ }^{39}$ The protective potency of insulin-like growth factor in cartilage degradation has been reported previously. ${ }^{41-43}$ Transforming growth factor $\beta$ inhibited IL-1 induced proteoglycan degradation but had no effect on the spontaneously occurring loss of newly formed proteoglycans. In an earlier report describing in vitro TGF- $\beta$ effects on proteoglycan loss from sliced cartilage $^{19}$ TGF- $\beta$ also inhibited spontaneously occurring proteoglycan loss. The importance of our observation is that for the first time we found evidence indicating that TGF- $\beta$ modulation of $\mathrm{IL}-1$ induced proteoglycan degradation is specific, independent of TGF$\beta$ effects on basal degradation. Possibly IL-1 
induces a separate set of proteases, different from the proteases taking part in normal turnover, that can be modulated specifically by TGF- $\beta$. Whether TGF- $\beta$ mainly influences the production of proteases or protease inhibitors $^{32} 44-46$ remains to be investigated. Another possible mechanism for specific TGF$\beta$ modulation of IL-1 induced proteoglycan degradation could be that TGF- $\beta$, in contrast with other growth factors, downregulates IL-1 receptor expression. ${ }^{17}{ }^{47}$ Induction of an IL-1 receptor antagonist protein by $\mathrm{TGF}-\beta$ in peripheral blood monocytes has also been reported. $^{48}$

The only previous report describing the effects of TGF- $\beta$ on proteoglycan synthesis in articular cartilage was that by Morales and Roberts. ${ }^{40}$ They used long term cultures of sliced bovine cartilage. In our studies we cultured for only two days, the time necessary to obtain a maximum IL-1 effect on proteoglycan synthesis. Again, the presence of insulin-like growth factor appeared to be important for stabilisation of proteoglycan metabolism in our patellae culture system. In the absence of insulin-like growth factor, TGF$\beta$ (400 pmol/1, 48 hours) stimulated both IL1 suppressed and spontaneously occurring proteoglycan synthesis. Chandrasekhar and Harvey ${ }^{18}$ found the same trend in monolayers of articular chondrocytes. In earlier studies performed in our laboratory, ${ }^{43}$ TGF- $\beta(0-200$ $\mathrm{pmol} / \mathrm{l}$ ) was found to have no effect on proteoglycan synthesis in short term experiments. In addition, also in vivo, we saw no effect of TGF- $\beta$ on basal proteoglycan synthesis 24 hours after intra-articular injections. A trend is noted that stimulating TGF- $\beta$ effects only appear when cartilage slices have been in culture for some time. A plausible explanation seems to be that TGF- $\beta$ has no stimulating effect on proteoglycan synthesis of normal articular chondrocytes, but becomes effective when the phenotype of articular chondrocytes has changed owing to prolonged culture or exposure to, for example, cytokines. Phenotype dependent receptor expression could be an explanation for the late onset of stimulating responses to TGF- $\beta$. Moreover, it has been reported that TGF- $\beta$ induces phenotype changes itself. ${ }^{49}$ This could indicate that after 48 hours of culture in the presence of TGF- $\beta$ and without insulin-like growth factor, the effects of TGF- $\beta$ on proteoglycan synthesis no longer reflect the in vivo situation. In our studies, when we cultured for two days in the presence of insulinlike growth factor, which is known to stimulate proteoglycan synthesis on its own ${ }^{33} 344243$ and to protect against phenotype changes, ${ }^{49} \mathrm{TGF}-$ $\beta$ had no extra effect on either IL- 1 suppressed or basal proteoglycan synthesis.

Conditions do exist where TGF- $\beta$ influences proteoglycan synthesis in spite of the presence of growth factors. During a phase of ex vivo recovery of IL-1 suppressed proteoglycan synthesis, TGF- $\beta$ can stimulate this process, whatever the mechanism involved.

In accordance with previously published work, ${ }^{50-53}$ TGF- $\beta$ injected into the knee joint had a clear chemoattractive capacity. The predominant inflammatory cells were polymorphonuclear leucocytes. This was also noted in studies performed in the knee of rats, ${ }^{52}$ whereas in the ankle joints of rats ${ }^{51}$ most infiltrating leucocytes were of monocytic lineage.

In vivo modulation of basal and IL-1 affected proteoglycan metabolism in articular cartilage by TGF- $\beta$ has not been described previously. Transforming growth factor $\beta$ injected into the joint caused a considerable reduction of IL-1 - induced proteoglycan degradation. This is in accordance with the in vitro observations. In contrast with the in vitro treatments, where TGF- $\beta$ had no significant effect, basal proteoglycan degradation was stimulated after TGF- $\beta$ injections. A possible explanation for this difference could be the inflammatory potential of TGF- $\beta$. It clearly induces inflammation and may therefore be indirectly responsible for enhanced degradation. The proinflammatory effect of TGF- $\beta$ could thus mask part of the protection against IL-1 induced proteoglycan degradation that is offered by TGF- $\beta$. The fact that TGF- $\beta$ injected intra-articularly caused marked effects, namely extra proteoglycan degradation and an influx of inflammatory cells, indicates that the endogenous TGF- $\beta$ in the noninflamed joint is either in a latent form or present in too low amounts, or controlled by inhibitors.

In vivo studies on proteoglycan synthesis show that TGF- $\beta$ had different effects on basal proteoglycan synthesis and suppressed proteoglycan synthesis after IL-1 treatment. The observation that basal proteoglycan synthesis is not influenced by TGF- $\beta$ is in agreement with its in vitro effects in the presence of a physiological insulin-like growth factor concentration, maintaining in vitro proteoglycan metabolism at levels similar to the normal in vivo conditions. In contrast with insulin-like growth factor cultures, TGF- $\beta$ in vivo decreased the suppression of proteoglycan synthesis induced by IL-1. Maybe this specific TGF- $\beta$ modulation of IL- 1 effects acts via TGF- $\beta$ downregulation of IL-1 receptors. ${ }^{47}$ Whatever is the mechanism of TGF- $\beta$ inhibition of IL-1 induced suppression of proteoglycan synthesis in vivo, histology shows that TGF- $\beta$ did not inhibit the IL-1 induced influx of inflammatory cells into the joint; TGF- $\beta$ might, however, suppress the production of cytokines, ${ }^{54}$ oxygen metabolites, ${ }^{55-57}$ or proteases by these cells. It has been reported that TGF- $\beta$ can cause defective phagocytic function of polymorphonuclear leucocytes. ${ }^{58}$ Moreover, TGF- $\beta$ can also regulate the production of other growth factors or their receptors, or both. ${ }^{59-62}$

We conclude that TGF- $\beta$ is able to block a considerable part of the IL-1 induced proteoglycan degradation and suppression of proteoglycan synthesis in articular cartilage. In the light of the destructive effect of IL-1 during arthritis we suggest an important protective function of TGF- $\beta$ for articular cartilage extracellular matrix. 
This work was supported by the Dutch League Agains Rheumatism. Recombinant murine interleukin $1 \alpha$ was kindly supplied by Dr I G Otterness (Pfizer Central Research, Groton, CT, USA). Purified human transforming growth factor $\beta 1$ was supplied by Dr A Purchio (Oncogen, Seattle, WA, USA) or by Dr C R Steffen (Collagen Corp, Palo Alto, CA, USA).

1 Pettipher E R, Higgs G A, Henderson B. Interleukin induces leukocyte infiltration and cartilage proteoglycan induces leukocyte infiltration and cartilage proteoglycan 1986; 83: 8749-53.

2 Miossec P, Cavender D, Ziff M. Interleukin 1 derived from human endothelial cells enhances the binding and chemotactic step of $\mathrm{T}$ lymphocyte emigration. Clin Exp Immunol 1988; 73: 250-4

3 Wancowicz Z, Megyeri P, Issekutz A. Synergy between tumour necrosis factor $\alpha$ and interleukin-1 in the induction of polymorphonuclear leukocyte migration during inflammation. $\mathcal{F}$ Leukocyte Biol 1988; 43: 349-56.

4 Sayers T J, Wiltrout T A, Bull C A, Denn A C, Pilaro A M, Lokesh B. Effect of cytokines on polymorphonuclear neutrophil infiltration in the mouse. F Immunol 1988; 141: 1670-7.

5 Bird T A, Saklatvala J. Identification of a common class of high affinity receptors for both types of porcin interleukin-1 on connective tissue cells. Nature 1986; 324 263-6.

6 Dingle J T, Page Thomas D P, King B, Bard D R. In vivo studies of articular tissue damage mediated by catabolin interleukin 1. Ann Rheum Dis 1987; 46: 527-33.

7 Van den Berg W B, van de Loo F A J, Zwarts W A, Otterness I G. Effects of murine recombinant interleukin 1 on intact homologous articular cartilage: a quantitative and autoradiographic study. Ann Rheum Dis 1988; 47: and autorac 63 .

8 Hubbard J R, Steinberg J J, Bednar M S, Sledge C B. Effect of purified human interleukin-1 on cartilage degradation. f Orthop Res 1988; 6: 180-7.

9 Smith R L, Allison A C, Schurman D J. Induction of articular cartilage degradation by recombinant interleukin $1 \alpha$ and $1 \beta$. Connect Tiss Res 1989; 18: 307-16.

10 Arner E C, Pratta M A. Independent effects of interleukin1 on proteoglycan breakdown, proteoglycan synthesis, and prostaglandin $\mathrm{E}_{2}$ release from cartilage in organ and prostaglandin $\mathrm{E}_{2}$ release from cart

11 Smith R J, Rohloff N A, Sam L M, Justen J M, Deibel M $R$, Cornette J C. Recombinant human interleukin-1 $\alpha$ and recombinant human interleukin- $1 \beta$ stimulate cartilage matrix degradation and inhibit glycosaminoglycan synthesis. Inflammation 1989; 13: 367-82.

12 Campbell I K, Last K, Novak U, Lund L R, Hamilton JA Recombinant human interleukin-1 inhibits plasminogen activator inhibitor-1 (PAI-I) production by human articular cartilage and chondrocytes. Biochem Biophys Res Commun 1991; 174: 251-7.

13 Miossec P, Dinarello C, Ziff $M$. Interleukin-1 lymphocyte chemotactic activity in rheumatoid arthritis synovial fluid. Arthritis Rheum 1986; 29: 461-9.

14 Hopkins S J, Humphreys M, Jayson M I V. Cytokines in synovial fluid. I. The presence of biologically active and immunoreactive IL-1. Clin Exp Immunol 1988; 72 422-7.

15 Rooney M, Symons J A, Duff G W. Interleukin 1 beta in synovial fluid is related to local disease activity in rheumatoid arthritis. Rheumatol Int 1990; 10: 217-9.

16 Wahl S M, Hunt D A, Wong H L, et al. Transforming growth factor $\beta$ is a potent immunosuppressive agent that inhibits IL-1-dependent lymphocyte proliferation. $\mathcal{F}$ Immunol 1988; 140: 3026-32.

17 Dubois C M, Ruscetti F W, Palaszynski E W, Falk L A $\beta$ is a potent inhibitor of interleukin-1 (IL-1) receptor expression: proposed mechanism of inhibition of IL-1 expression: proposed mechanism of
action. $\mathcal{F}$ Exp Med 1990; 172: 737-44.

18 Chandrasekhar S, Harvey A K. Transforming growth factor- $\beta$ is a potent inhibitor of IL-1 induced proteas activity and cartilage proteoglycan degradation: Biochem Biophys Res Commun 1988; 157: 1352-9.

19 Andrews H J, Edwards T A, Cawston T E, Hazleman B L. Transforming growth factor-beta causes partial inhibition of interleukin 1 stimulated cartilage degradation in vitro. Biochem Biophys Res Commun 1989; 162: 144-50.

20 Wahl S M, Hunt D A, Bansal G, McCartney-Francis N, Ellingsworth L, Allen J B. Bacterial cell wall-induced immunosuppression. Role of transforming growth factor B. F Exp Med 1988; 168: 1403-17.

21 Wahl S M, McCartney-Francis N, Mergenhagen S E Inflammatory and immunomodulatory roles of TGF- $\beta$. Immunol Today 1989; 10: 258-61.

22 Kehrl J H, Taylor A S, Delsing G A, Roberts A B, Sporn $M$ B, Fauci A S. Further studies of the role of transforming growth factor- $\beta$ in human $B$ cell function. f Immunol 1989; 143: 1868-74.

23 Kim K J, Abrams J, Alphonso M, Pearce M, Thorbecke G J, Palladino M A. Role of endogenously produced interleukin- 6 as a second signal in murine thymocyte proliferation induced by multiple cytokines: regulatory effects of transforming growth factor- $\beta$. Cell Immunol 1990; 131: 261-71.

24 Espevik T, Waage A, Faxvaag A, Shalaby M R. Regulation of interleukin-2 and interleukin-6 production from T-cells: involvement of interleukin- $1 \beta$ and transforming growth factor- $\beta$. Cell Immunol 1990; 126: 47-56.
25 Brandes M E, Allen J B, Ogawa Y, Wahl S M. Transforming growth factor $\beta 1$ suppresses acute and chronic arthritis in experimental animals. $\mathcal{f}$ Clin Invest 1991; 87: 1108-13.

26 Fava R, Olsen N, Keski-Oja J, Moses H, Pincus T. Active and latent forms of transforming growth factor $\beta$ activity in synovial effusions. $\mathcal{F} \operatorname{Exp} M e d$ 1989; 169: 291-6.

27 Lotz M, Kekow J, Carson D A. Transforming growth factor- $\beta$ and cellular immune responses in synovial fluids. factor- $\beta$ and cellular immune $1990 ; 144:$ 4189-94.

28 Miossec P, Naviliat M, d'Angeac A D, Sany J, Banchereau J. Low levels of interleukin-4 and high levels of transforming growth factor $\beta$ in rheumatoid synovitis. transforming growth factor $\beta$ in
Arthritis Rheum 1990; 33: $1180-7$.

29 Wahl S M, Allen J B, Wong $\mathrm{H}$ L, Dougherty S F, Ellingsworth L R. Antagonistic and agonistic effects of transforming growth factor- $\beta$ and IL- 1 in rheumatoid synovium. F Immunol 1990; 145: 2514-9.

30 Hiraki Y, Inoue H, Hirai R, Kato Y, Suzuki F. Effect of transforming growth factor $\beta$ on cell proliferation and glycosaminoglycan synthesis by rabbit growth-plate chondrocytes in culture. Biochim Biophys Acta 1988; 969: 91-9.

31 Redini F, Galera P, Mauviel A, Loyau G, Pujol J-P. Transforming growth factor $\beta$ stimulates collagen and glycosaminoglycan biosynthesis in cultured rabbi articular chondrocytes. FEBS Lett 1988; 234: 172-6.

32 Overall C M, Wrana J L, Sodek J. Independent regulation of collagenase, $72-\mathrm{kDa}$ progelatinase, and metalloendoproteinase inhibitor expression in human fibroblasts by transforming growth factor- $\beta$. $\mathcal{F}$ Biol Chem 1989; 264 1860-9.

33 McQuillan D J, Handley C J, Campbell M A, Bolis S, Milway V E, Herington A C. Stimulation of proteoglycan biosynthesis by serum and insulin-like growth factor- 1 in cultured bovine articular cartilage. Biochem $\mathcal{F} 1986 ; 240$; cultured

34 Schalkwijk J, Joosten L A B, van den Berg W B, van Wyk $\mathrm{J} J$, van de Putte L B A. Insulin-like growth factor stimulation of chondrocyte proteoglycan synthesis by human synovial fluid. Arthritis Rheum 1989; 32: 66-71.

35 van den Berg W B, Kruijsen M W M, van de Putte L B A. The mouse patella assay: an easy method of quantitating articular cartilage chondrocyte function in vivo and in vitro. Rheumatol Int 1982; 1: 165-9.

36 De Vries B J, van den Berg W B, Vitters E, van de Putte L B A. Quantitation of glycosaminoglycan metabolism in anatomically intact articular cartilage of the mouse
patella: in vitro and in vivo studies with ${ }^{35} \mathrm{~S}$-sulfate, patella: in vitro and in vivo studies with ${ }^{35} \mathrm{~S}$-sulfate, ${ }^{3} \mathrm{H}$-gluc

37 Van den Berg W B, Kruijsen M W M, van de Putte L B $A$, van Beusekom $H$ J, van der Sluis-van der Pol $M$ Zwarts W A. Antigen-induced and zymosan-induced arthritis in mice: studies on in vivo cartilage proteoglycan synthesis and chondrocyte death. Br f Exp Pathol 1981; 62: 308-16.

38 van de Loo A A J, van den Berg W B. Effects of murine recombinant interleukin 1 on synovial joints in mice: measurement of patellar cartilage metabolism and joint measurement of patellar cartilage metabolism and
inflammation. Ann Rheum Dis 1990; 49: 238-45.

39 van Beuningen H M, Arntz O J, van den Berg W B. In vivo effects of interleukin-1 on articular cartilage: prolongation of proteoglycan metabolic disturbances in old mice. Arthritis Rheum 1991; 34: 606-15.

40 Morales T I, Roberts A B. Transforming growth factor $\beta$ regulates the metabolism of proteoglycans in bovine cartilage organ cultures. $\mathcal{F}$ Biol Chem 1988; 263: 12828-31.

41 Luyten F P, Hascall V C, Nissley S P, Morales T I, Reddi A H. Insulin-like growth factors maintain steady-state metabolism of proteoglycans in bovine articular cartilage explants. Arch Biochem Biophys 1988; 267: 416-25.

42 Tyler J A. Insulin-like growth factor 1 can decrease degradation and promote synthesis of proteoglycan in cartilage exposed to cytokines. Biochem $\mathcal{f} 1989 ; 260$ : 543-8.

43 van der Kraan P M, Vitters E L, van den Berg W B. Inhibition of proteoglycan synthesis by transforming growth factor $\beta$ in anatomically intact articular cartilage of murine patellae. Ann Rheum Dis 1992; 51: 643-7.

44 Edwards D R, Murphy G, Reynolds J J, Whitham S E, Docherty A J P, Angel P, Heath J K. Transforming growth factor beta modulates the expression of collagenase and metalloprotein

45 Saksela O, Moscatelli D, Rifkin D B. The opposing effects of basic fibroblast growth factor and transforming growth factor beta on the regulation of plasminogen activato activity in capillary endothelial cells. $\mathcal{F}$ Cell Biol 1987; 105 957-63.

46 Reilly C F, McFall R C. Platelet-derived growth factor and transforming growth factor- $\beta$ regulate plasminogen activator inhibitor-1 synthesis in vascular smooth muscle cells. F Biol Chem 1991; 266: 9419-27.

47 Harvey A K, Hrubey P S, Chandrasekhar S. Transforming growth factor- $\beta$ inhibition of interleukin-1 activity growth factor- $\beta$ inhibition of interleukin-1 activity
involves down-regulation of interleukin- 1 receptors on involves down-regulation of interleukin-1 recep
chondrocytes. Exp Cell Res 1991; 195: 376-85.

48 Turner M, Chantry D, Katsikis P, et al. Induction of the interleukin 1 receptor antagonist protein by transforming interleukin 1 receptor antagonist protein by transform
growth factor- $\beta$. Eur f Immunol 1991; 21: 1635-9.

49 Inoue H, Kato Y, Iwamoto M, Hiraki Y, Sakuda M, Suzuki F. Stimulation of proteoglycan synthesis by morphological transformed chondrocytes grown in the presence of fibroblast growth factor and transforming
growth factor-beta. $\mathcal{F}$ Cell Physiol 1989; 138: 329-37. 
50 Wiseman D M, Polverini P J, Kamp D W, Leibovich S J Transforming growth factor-beta (TGF $\beta$ ) is chemotactic
for human monocytes and induces their expression of angiogenic activity. Biochem Biophys Res Commun 1988; 157: 793-800.

51 Allen J B, Manthey C L, Hand A R, Ohura K, Ellingsworth L, Wahl S M. Rapid onset synovial inflammation and hyperplasia induced by transforming growth factor $\beta$. $\mathcal{F}$ Exp Med 1990; 171: 231-47.

52 Fava R A, Olsen N J, Postlethwaite A E, et al. Transforming growth factor $\beta 1$ (TGF- $\beta 1$ ) induced neutrophil recruitment to synovial tissues: implications for TGFrecruitment to synovial tissues: implications for TGFB-driven synovial inflam

53 Adams D H, Hathaway M, Shaw J, et al. Transforming growth factor- $\beta$ induces human $T$ lymphocyte migration in vitro. F Immunol 1991; 147: 609-12.

54 Chantry D, Turner M, Abney E, Feldmann M. Modulation of cytokine production by transforming growth factor $\beta$. f Immunol 1989; 142: 4295-300.

55 Nelson B J, Ralph P, Green S J, Nacy C A. Differential susceptibility of activated macrophage cytotoxic effector reactions to the suppressive effects of transforming growth factor- $\beta 1$. F Immunol 1991; 146: 1849-57.

56 Ding A, Nathan C F, Graycar J, Derynck R, Stuehr D J, Srimal $S$. Macrophage deactivating factor and transforming growth factors- $\beta 1,-\beta 2$, and $-\beta 3$ inhibit induction of macrophage nitrogen oxide synthesis by IFNY. F Immunol 1990; 145: 940-4.

57 Tsunawaki S, Sporn M, Ding A, Nathan C. Deactivation of macrophages by transforming growth factor- $\beta$. Nature 1988; 334: 260-2.

58 Gresham H D, Ray C J, O'Sullivan F X. Defective neutrophil function in the autoimmune mouse strain MRU/1pr. Potential role of transforming growth factor- $\beta$. f Immunol 1991; 146: 3911-21.

59 Bryckaert $M$ C, Lindroth $M$, Lonn A, Tobelem G Wasteson A. Transforming growth factor (TGF $\beta$ ) decreases the proliferation of human bone marrow fibroblasts by inhibiting the platelet-derived growth factor (PDGF) binding. Exp Cell Res 1988; 179: 311-21.

60 Thompson K L, Assoian R, Rosner M R. Transforming growth factor increases transcription of the gene encoding the epidermal growth factor receptor and fibronectin in normal rat kidney fibroblasts. $7 \mathrm{Biol}$ Chem 1988; 263: 19519-24.

61 McCartney-Francis N, Mizel D, Wong H, Wahl L, Wahl S TGF- $\beta$ regulates production of growth factors and TGF$\beta$ by human peripheral blood monocytes. Growth Factors 1990; 4: 27-35.

62 Elford P R, Lamberts S W J Contrasting modulation by transforming growth factor- $\beta-1$ of insulin-like growth fransforming growth factor- $\beta-1$ of insulin-like growth Endocrinology 1990; 127: 1635-9. 